\title{
Increasing photonics awareness for youngsters using technology boot camps
}

\section{Chrysanthos Panayiotou}

Chrysanthos Panayiotou, "Increasing photonics awareness for youngsters using technology boot camps," Proc. SPIE 11143, Fifteenth Conference on Education and Training in Optics and Photonics: ETOP 2019, 1114320 (2 July 2019); doi: 10.1117/12.2523804

SPIE Event: Fifteenth Conference on Education and Training in Optics and Photonics: ETOP 2019, 2019, Quebec City, Quebec, Canada 


\title{
Increasing Photonics Awareness for Youngsters Using Technology Boot Camps

\author{
Chrysanthos Panayiotou, Ed.D.
}

\author{
LASER-TEC, Center for Laser and Fiber Optics Education \\ Indian River State College, 3209 Virginia Ave., Fort Pierce, FL, USA 24981-5596
}

\begin{abstract}
In Florida, and the United States in general, we are experiencing low interest in our photonics technician programs from students finishing high school. The National Science Foundation and many other national organizations have been promoting STEM (Science, Technology, Engineering and Mathematics) during the last ten years, which has increased the interest and awareness among students and parents. However, the large majority of the students who show interest in STEM opt for an education at a university where they can obtain a bachelor's degree.

To attract more students to a two-year Associate degree in Photonics we established a year-long program of short technology boot camps for students who are in middle school or their first grade of high school. We borrowed the idea from after-school music lessons or camps, and soccer or other sports activities. The students are weekly engaged in these mostly fun activities during after-school hours, and for a long period of time lasting many months. Music lessons, for example, are typically offered once a week, but last from 9-12 months. Sports activities run as long as an entire season.

We hypothesized that the continuous interaction with the subject allows a young person to develop skills, confidence, and experience that eventually influence their decision to continue further studies that will lead to a career. To test this idea, we created a series of technology camps that we offered during the entire year, after school hours, allowing an interested student to pursue technological education throughout the year. The technological awareness and continuous engagement with hands on activities enabled the youngsters to discover if they had talents or proclivities that would trigger the desire for further studies in technology, engineering, or science. This paper describes the different technology camps, the data gathered, the outcomes and the results of testing our hypothesis.
\end{abstract}

Keywords: Photonics, Outreach, STEM, camps, summer-camps, Lasers, Fiber optics, awareness, technology, engineering.

\section{INTRODUCTION}

The rapid technological progress we are experiencing today is fueled by the advancements in science, engineering and technology that have been occurring at an accelerated pace since 1950. The transistor, the integrated circuit, the laser, and the microprocessor were the driving technologies that enabled the personal computer, the internet, industrial automation, scientific and business computing, just to name the few important areas of application that affect our daily lives. All of these technological achievements have created new industries, success for many companies, and wealth for people that pursued careers in the newly established occupations. Programming computers or robotic automated systems, designing, building and maintaining laser systems, creating the internet with fiber optics, and maintaining the World Wide Web are some of these new occupations.

Despite these astonishing advances, the United States and other Western countries are experiencing a shortage of people entering the fields of science, engineering, and technology which are necessary to maintain and expand our technological achievements. In the United States the number of graduating computer scientists, engineers, and technicians, has not kept up with the increasing demand, and as a consequence many companies have difficulty finding talented individuals who want to enter these fields ${ }^{1}$. 
To address this problem in our local region of southeast Florida, Indian River State College had offered, for years, youth technology camps in the summer time. The summer camps were always well received, with almost full attendance for many years. However, the college enrollment in technical programs has not seen any corresponding increase. In our attempt to understand this disparity we established the hypothesis that even though youngsters enthusiastically attend the summer technology camps, once they get back to their normal routine they forget about them and other distractions are replacing their interest and enthusiasm. To maintain and increase their enthusiasm, logically thinking, one needs to sustain and feed that interest for a prolonged period of time to make any permanent changes in the desires of these adolescent age students. To test this hypothesis, we established a year-long series of technology camps that will sustain their interests and enthusiasm for a long period of time and turn it into a desire to study a technical field that will lead to one of the careers we experience shortages in today.

\section{TECHNOLOGY CAMPS}

Four different technology camps were created that interweave photonics, electronics, and computer coding. The first three camps are centered around the popular Arduino microcontroller board, which is used to control the photonics, electronics or automation components under a program written by the camper. The descriptions of the camps and their content are listed below.

\subsection{Camp 1. Arduino I - Visible Light Spectrum}

In this camp, the students discovered the world of computer coding using the Arduino microcontroller. They created computer code that turns the Arduino into a controller that interacts with electronic circuits and automates simple tasks. The camp was presented as an opportunity for a youngster to discover if he/she has a knack for computer coding, electronics, and photonics technology.

Some of the tasks performed at this camp were building simple LED circuits, mixing and changing colors with coding, creating personalized messages, sending and receiving digital and audible commands, learning how TV remote control works, figuring out if plants need watering with moisture sensing, and creating a clock on the Arduino microcontroller using code.

Every camper received their own kit with the Arduino microcontroller and all the parts and hardware needed to perform all the projects. The idea here is that having these parts at home will enable the adolescent student to continue experimenting and learning past the camp period, maintaining and growing the developed interest.

All the camps were taught by subject matter experts who were well-versed in the field of electronics and programming, and very enthusiastic about the subject and their teaching.

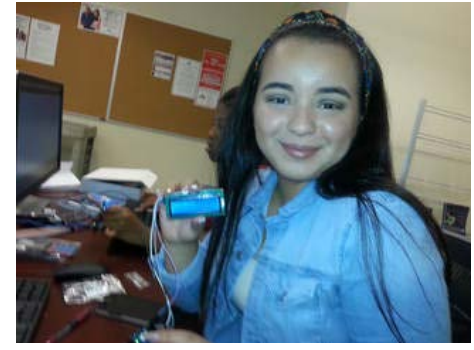

Hello World! LCD Project

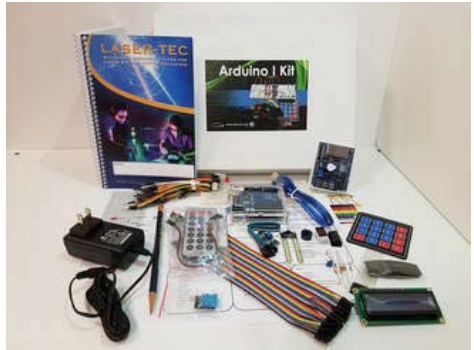

Arduino I Kit

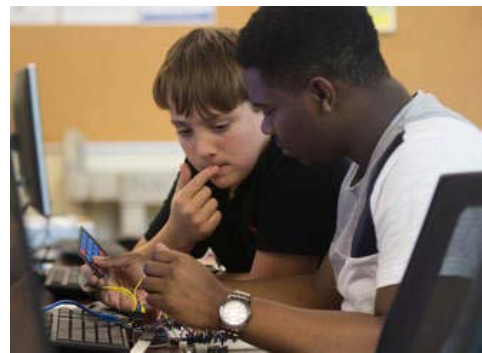

4x4 Keypad Matrix Project

Fig.1 Pictures of students and the kit used in Arduino I - Visible Light Spectrum camp 


\subsection{Camp 2. Arduino II - Wireless Technologies}

In this camp, the students expanded their knowledge of computer coding using the Arduino microcontroller. They wrote computer code to interact with electronic circuits that can "automate the world". The projects were carefully selected to show the student that a hobby can turn into a high-demand career.

Some of the tasks performed at this camp were programming an LED matrix, sending and receiving data using radio frequencies, creating a personal controlled-access entry using RFID, and experimenting by adding Bluetooth and wireless capabilities to the Arduino. They also learned about the speed of sound, and how sonar is used to measure distance. As a final project every camper built their own Arduino board from scratch!

Every camper received their own kit with the Arduino microcontroller and all the parts and hardware needed to perform all the projects. The idea here is that having these parts at home will enable the adolescent student to continue experimenting and learning past the camp period, maintaining and growing the interest developed. It also enabled the students to show their parents, siblings, and others what they had learned and create a positive and reinforcing environment at home.

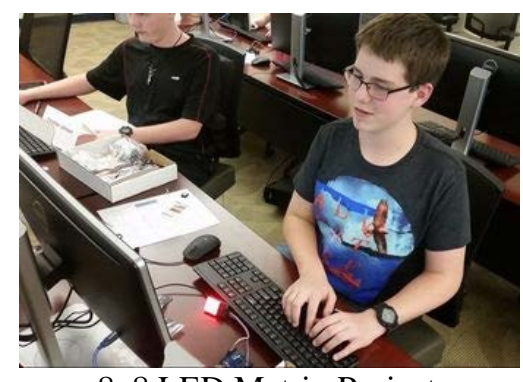

8x8 LED Matrix Project

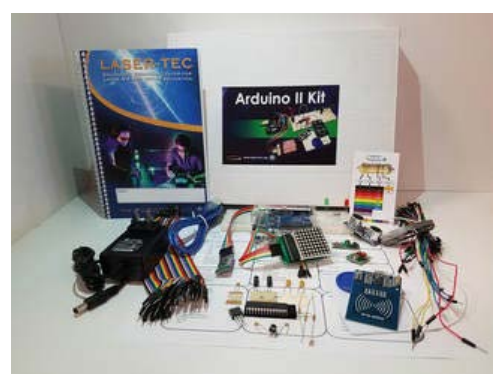

Arduino II Kit

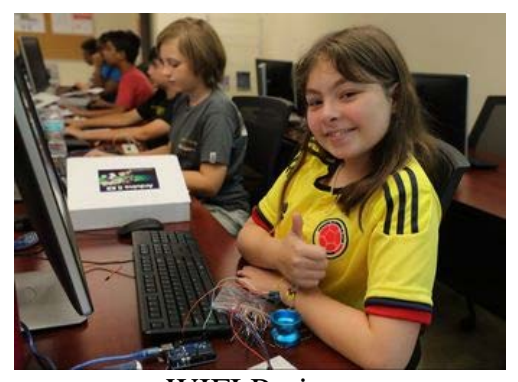

WIFI Project

Fig.2 Pictures of students and the kit used in Arduino II - Wireless Technologies camp

\subsection{Camp 3. Arduino III - Game Programming}

In this camp, the student entered the world where $\mathrm{C}++$ and Java meet. The campers built electronic circuits to control software, and turned retro games into real-life functioning models.

Some of the tasks performed at this camp were using the Arduino as a synthesizer to replicate the theme songs from retro games, and creating a clock that displays the lunar cycle, time of day, day of week, week of month, and month of year. They developed an electronic circuit that senses color and can reproduce that same color. Students coded "Pong" in Java, developed a virtual "Etch-A-Sketch" using Arduino as the controller and a computer monitor as the display, and created a rotating SONAR device that resembles technology used on submarines. They also developed a game similar to Arkanoid, using $\mathrm{C}++$ \& Java.

Every camper received their own kit with the Arduino microcontroller and all the parts and hardware needed to perform all the projects. The idea here is that having these parts at home will enable the adolescent student to continue experimenting and learning past the camp period, maintaining and growing the interest developed. 


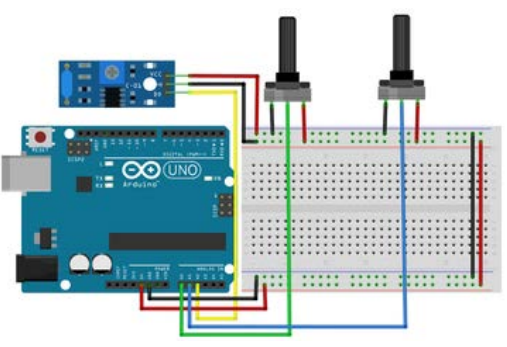

Etch-A-Sketch Project

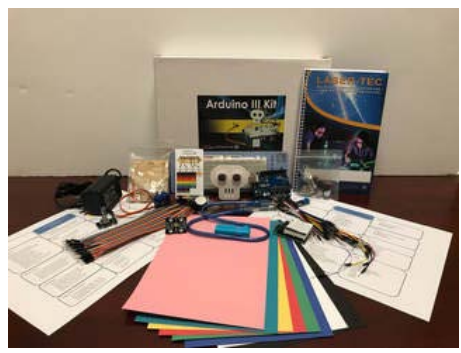

Arduino III Kit

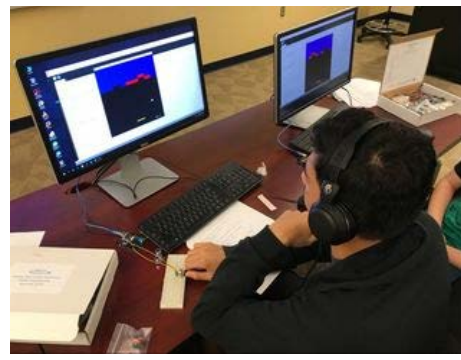

Arkanoid Project

Fig. 3 Pictures of students and the kit used in Arduino III - Game Programming camp

\subsection{Camp 4. Electronics Maker}

In this camp, the students explored the world of electronic circuitry and how different components behave and create interesting circuits when arranged together in various ways. They also built prototype circuits on a breadboard and then transferred it to a Printed Circuit Board (PCB). They learned the art of soldering and desoldering utilizing professionalgrade equipment. In this camp the students were also introduced to function generators, oscilloscopes, multi-meters, and more.

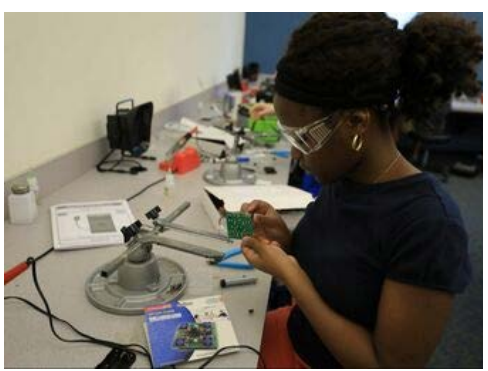

Brain Game Project

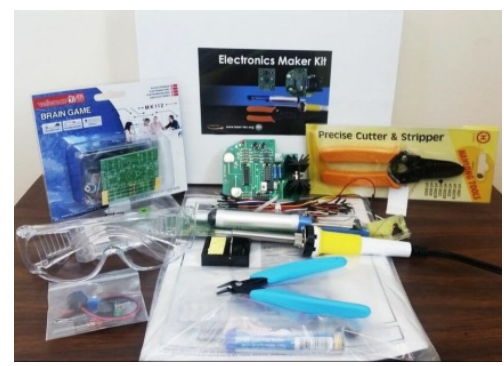

Electronics Maker Kit

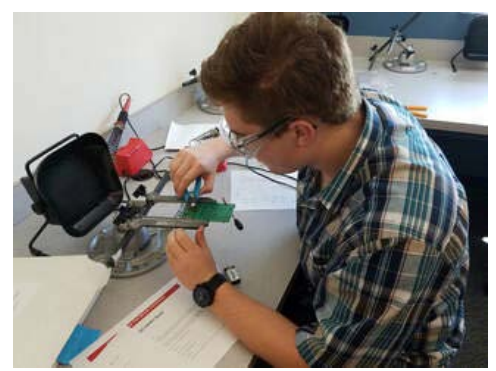

Solder Practice Board Project

Fig.4 Pictures of students and the kit used in Electronics Maker camp

\section{RESULTS}

The camps were offered from October 2016 to May 2019, with 282 participants. Out of this population, 120 participants discovered that technology and engineering was interesting and worth taking more camps for further learning and exploration. These 120 participants became the sample of our study. We surveyed these participants six months after finishing the last camp, inquiring about their future college studies and career plans. The response rate of the survey was $60 \%$, and $93 \%$ of the responders indicated that they would be applying for a technical field at a college or university during their senior year in high school. 
Table 1. List of all youth camps

\begin{tabular}{|c|c|c|c|}
\hline Name of Camp & \# of Times Offered & Dates & Attendance per camp \\
\hline Arduino I: Visible Light Spectrum & 8 & $\begin{array}{l}\text { Oct 19-Dec 14, } 2016 \\
\text { Jan 11-Mar 1, } 2017 \\
\text { March 27-May 15, } 2017 \\
\text { June 19-23, } 2017 \\
\text { July 24-28, } 2017 \\
\text { Oct 25-Dec 13, } 2017 \\
\text { June 11-14, } 2018 \\
\text { Jan 16-March 6, } 2019\end{array}$ & $\begin{array}{l}20 \\
11 \\
6 \\
5 \\
7 \\
10 \\
12 \\
6\end{array}$ \\
\hline Arduino II: Wireless Technologies & 4 & $\begin{array}{l}\text { March 29-May 17, } 2017 \\
\text { Jan } 17-\text { March 7, } 2018 \\
\text { June } 25-28,2018 \\
\text { August } 29-\text { Oct } 10,2018\end{array}$ & $\begin{array}{l}11 \\
8 \\
13 \\
8\end{array}$ \\
\hline Arduino III: Game Programming & 4 & $\begin{array}{l}\text { July 9-12, } 2018 \\
\text { July } 16-19,2018 \\
\text { Oct 24-Dec 12, } 2018 \\
\text { March 27-May 15, } 2019\end{array}$ & $\begin{array}{l}15 \\
12 \\
12 \\
10\end{array}$ \\
\hline Electronics Maker & 3 & $\begin{array}{l}\text { July 10-14, } 2017 \\
\text { July 31-Aug 4, } 2017 \\
\text { June 18-21, } 2018 \\
\end{array}$ & $\begin{array}{l}6 \\
9 \\
15 \\
\end{array}$ \\
\hline Lasers and Fiber Optics & 3 & $\begin{array}{l}\text { June 13-17, } 2016 \\
\text { June 12-16, } 2017 \\
\text { July 17-21, } 2017 \\
\end{array}$ & $\begin{array}{l}13 \\
14 \\
16 \\
\end{array}$ \\
\hline Robotics and Arduino & 1 & June 27-July 1, 2016 & 16 \\
\hline Tech Like A Girl & 2 & $\begin{array}{l}\text { Jan 28-March 11, } 2017 \\
\text { Jan 20-Feb 10, } 2018\end{array}$ & $\begin{array}{l}16 \\
11\end{array}$ \\
\hline TOTAL & 25 & & 282 \\
\hline
\end{tabular}

\section{CONCLUSIONS}

Our study tested the hypothesis that continuous engagement with technology over a long period of time of nine to twelve months should create a desire to enter a technical field of study for those who have the proclivity and talents that are needed for such studies.

Our sample was 120 participants who took more than one camp, and we could therefore use them to test our hypothesis. When surveyed six months after finishing the last camp, 93\% of responders indicated that they were planning to apply for a technical field of study at a college or university in their senior year of study at high school. This was a small scale and by no means scientific study, but it verified our hypothesis, and is in agreement with the social science and psychology literature suggesting that positive engagement and exposure of youngsters to skills relates to career choice ${ }^{2}$.

The addition of advisor intervention, by the end of the last camp, to encourage registration and completion of Math and Science course requirements, will help prepare these 120 participants for our two-year photonics technician programs. Potential continuing higher-level camps that will be designed to maintain their interest in Photonics through their senior year of high school may also help keep them interested in studying at our particular institution, as a long-time relationship will have been developed. 
We plan to follow up with these 120 participants and survey them as they finish high school and enroll in a postsecondary institution to find out what their final choice of study will be.

\section{REFERENCES}

[1] Yi Xue and Richard C. Larson, "STEM crisis or STEM surplus? Yes and yes," Monthly Labor Review, U.S. Bureau of Labor Statistics, May 2015, https://doi.org/10.21916/mlr.2015.14.

[2] Elka Torpey, "Career planning for high schoolers," Career Outlook, U.S. Bureau of Labor Statistics, January 2015, https://www.bls.gov/careeroutlook/2015/article/career-planning-for-high-schoolers.htm 